\title{
Gestão da comunicação nas organizações: um estudo em dez ministérios brasileiros
}

\section{Communication management in organizations: a study in ten brazilian ministries}

Bianca Smolarek ${ }^{1}$

\section{Resumo}

O presente artigo relata os resultados de um estudo que se propõe a contribuir para a melhor compreensão sobre gestão da comunicação nas organizações. Os objetivos são mapear os aspectos mais destacados sobre competências e habilidades inerentes à função e apontar convergências e divergências encontradas durante a pesquisa. Por meio de revisão bibliográfica e de um estudo qualitativo - realizado junto a chefes das áreas de comunicação social de dez dos 15 maiores ministérios brasileiros -, o trabalho mostra que todos os anos centenas de profissionais ingressam na área de comunicação corporativa e que executam estratégias de comunicação ancoradas mais na assessoria de imprensa do que nas demais áreas da comunicação social. Uma das principais conclusões é a existência de assimetrias nas assessorias de comunicação dos ministérios visitados e na forma de pensar de seus gestores. O perfil básico do grupo estudado mostra que esse gestor tem cerca de 50 anos, vem da Região Sudeste, é jornalista, ocupa cargo comissionado, está na função há menos de dois anos e tem experiência anterior na imprensa e em comunicação pública. Em sua maioria, os gestores estudados atuam mais como jornalistas do que como gestores, assessoram mais do que planejam e enfrentam considerável dificuldade para promover comunicação integrada, medir resultados e executar atividades administrativas. Eles reconhecem como habilidades fundamentais aquelas relacionadas à assessoria de imprensa e muitas vezes questionam a necessidade de aprimorar competências de gestão e administrativas.

Palavras-chave: Gestão da comunicação. Gestor de comunicação. Planejamento em comunicação. Comunicação integrada. Comunicação pública.

\section{Abstract}

The study will contribute to a better understanding about communication management in organizations. The objectives are listing recurring activities in daily corporative communication managers, to map the most important aspects of skills and abilities inherent to the function and the main convergences and divergences found during the search. From a literature review and a qualitative study - arising from interviews with ten communication's managers from ten of the 15 largest Brazilian ministries -, the study shows that every year hundreds of professionals enter in the corporate communication trade and they usually mostly perform strategies based in the press office than in other areas of social communication. One of the conclusions is the asymmetry between the communication's departments of the ministries observed and the thought of their managers. The basic profile of the studied group is that this manager has about 50 years, comes from the Southeast Region, is a journalist, has a commissioned position, is in this role for less than two years, has worked in the press and has previous experience in public communication. Most of the studied managers act more like journalists than as managers, advising more than planning and facing considerable difficulty to promote integrated communication, measurement results and administrative activities. They recognize that those journalist's skills are very important for this job and most of them do not prioritize administrative and management skills.

Keywords: Communication management. Communication's manager. Communication planning. Integrated Communication. Public Communication. 


\section{Introdução}

O estudo aqui relatado foi apresentado ao Centro Universitário de Brasília (UniCEUB/ICPD), em abril de 2014, como pré-requisito para a obtenção de Certificado de Conclusão de Curso de Pós-Graduação Lato Sensu em Gestão da Comunicação nas Organizações. Ele aborda a gestão da comunicação como uma atividade cada vez mais considerada estratégica para o sucesso das organizações, tanto do setor privado quanto do público. Todos os anos, centenas de profissionais ingressam ou se especializam nessa área, cuja demanda é crescente. Como veremos mais à frente, o perfil desses profissionais é bem claro no Brasil (geralmente jornalistas, muitos oriundos das redações dos veículos de comunicação). Porém, o papel e o perfil de quem chefia essas áreas ainda não estão tão claros e, em várias organizações, a função acontece de acordo com o que pensa - e conquista - o detentor do cargo.

Há, entre os especialistas, uma variedade enorme de opiniões e interpretações sobre "quem são", ou "quem deveriam ser", os gestores da comunicação nas organizações - sua formação, experiência anterior, competências profissionais, atribuições do dia a dia, nível de decisão, entre outros. E é a essa questão que se dedica o trabalho aqui relatado.

O estudo se propõe a contribuir para a melhor compreensão sobre a gestão da comunicação nas organizações e sua relação tanto com conceitos estritamente de gestão (habilidades para liderar, tomar decisões, chefiar equipes e gerir recursos, por exemplo) como com conceitos de comunicação integrada (execução de estratégias que aliem diversas frentes da comunicação, como jornalismo, relações públicas, publicidade e propaganda, mídias digitais, comunicação interna, entre outras). Mais especificamente, os objetivos são observar os diferentes entendimentos sobre o tema (apresentados por profissionais da área), mapear os aspectos mais destacados sobre competências e habilidades inerentes à função e apontar as maiores convergências e divergências sobre o assunto encontradas durante a pesquisa.

Apesar da dificuldade em se obter, na literatura científica, títulos específicos sobre o tema, para alcançar os objetivos do trabalho, foi realizada revisão bibliográfica do assunto em obras e artigos de especialistas em comunicação corporativa. Também foi desenvolvido um estudo qualitativo envolvendo os chefes das áreas de comunicação de dez ministérios brasileiros. Por meio de entrevistas, cujo formato será detalhado adiante, foram colhidas suas impressões sobre o tema, além de experiências e opiniões. E, a partir das informações, foi traçado um perfil do grupo estudado.

Como a relevância maior do trabalho é contribuir para uma compreensão ampla sobre a gestão da comunicação nas organizações, em relação ao estudo qualitativo, vale destacar que não se pretende aqui expor ou detalhar individualmente o perfil de cada entrevistado ou do órgão onde atua. O que se busca é demonstrar quais aspectos do tema se revelaram mais comuns entre eles, assim como os mais contrastantes. Por isso, a identidade dos participantes do estudo não é mencionada.

O trabalho também não foi desenvolvido com a intenção de tratar a temática como uma verdade definitiva ou absoluta. "Os fenômenos e objetos do mundo não constituem um amontoado de coisas acabadas, mas em constante transformação", lembra Triviños (1987, p. 17). Porém, para embasar cientificamente o estudo, foi traçada uma metodologia clara e substancial, seguindo o materialismo dialético e evitando qualquer tratamento especulativo, de base filosófica idealista, sobre as informações (TRIVIÑOS, 1987, p. 18).

O conhecimento apreendido durante a revisão bibliográfica foi fundamental para embasar as atividades de apuração e análise realizadas no estudo qualitativo. A escolha por entrevistar dez gestores de comunicação de ministérios brasileiros se deve: primeiro, à preferência por se trabalhar com uma amostra, garantindo um mínimo de representatividade do conjunto de informações obtido; segundo porque os ministérios brasileiros são órgãos de estrutura, finalidade, atuação e diretrizes minimamente semelhantes, o que insere os entrevistados em um mesmo cenário e torna o perfil buscado mais próximo do real; terceiro pela relevância nacional da atuação desses órgãos e, portanto, de seus gestores.

A quantidade de entrevistados foi estipulada a partir das condições de pesquisa da autora dentro do método e dos prazos definidos. As dez entrevistas foram realizadas pela pesquisadora, individualmente, entre 13 de julho e 25 de setembro de 2012. Todas ocorreram pessoalmente, em ambientes institucionais (dentro das assessorias de comunicação social dos ministérios selecionados), mediante agendamento prévio e com uma hora de duração, em média.

O critério de seleção dos gestores procurados foi o porte das pastas do Ministério Brasileiro, nas quais eles 
atuam, considerando o valor do seu orçamento na Lei Orçamentária Anual (LOA) de 2012, publicada no Diário Oficial da União de 20 de janeiro daquele ano, como Lei $n^{\circ} 12.595$ de 19 de janeiro de 2012.

Levando-se em conta as possíveis dificuldades de agenda, foram enviados convites para participar do estudo a gestores de comunicação dos 15 maiores ministérios que, do maior para o menor, são: Previdência Social; Saúde; Educação; Defesa; Trabalho e Emprego; Desenvolvimento Social e Combate à Fome; Transportes; Cidades; Fazenda; Justiça; Agricultura, Pecuária e Abastecimento; Ciência, Tecnologia e Inovação; Planejamento, Orçamento e Gestão; Minas e Energia; e Integração Nacional.

Os dez gestores que aceitaram conceder entrevista ao estudo no prazo estipulado atuam, ou atuavam na época, nas pastas da Previdência Social; Educação; Defesa; Desenvolvimento Social e Combate à Fome; Transportes; Cidades; Fazenda; Agricultura, Pecuária e Abastecimento; Planejamento, Orçamento e Gestão; e Minas e Energia. Essa amostra reúne, portanto, dez dos 15 maiores ministérios brasileiros segundo a LOA 2012, estando sete deles entre os dez maiores. Juntas, essas dez pastas abarcaram um orçamento anual de mais de $\mathrm{R} \$ 616$ bilhões, $\mathrm{o}$ que representou aproximadamente $74 \%$ do orçamento de todo o Poder Executivo naquele ano.

Apesar de serem estruturas similares, as áreas de comunicação social dos ministérios estão organizadas de forma variada (algumas são lideradas pelo chefe da assessoria de comunicação social e outras por um assessor especial do ministro que está, hierarquicamente, acima do chefe da assessoria de comunicação social). Ao procurar esses departamentos, a autora foi recebida por sete chefes da assessoria de comunicação social, dois assessores especiais e um chefe da assessoria de imprensa. Essa estruturação e suas diferenças aparecem com mais detalhamento no item 3, onde estão apresentados os resultados do estudo qualitativo.

A técnica de entrevista adotada foi entrevista individual em profundidade que, como explica Duarte (2013, p. 1), é uma "técnica qualitativa que explora um assunto a partir da busca de informações, percepções e experiências de informantes, para analisá-las e apresentá-las de forma estruturada”. É um recurso metodológico que busca respostas a partir da experiência subjetiva da fonte e os dados não são apenas colhidos, mas também resultado de interpretação e reconstrução pelo pesquisador, em diálogo inteligente e crítico com a realidade (DUARTE, 2013, p. 1).
A entrevista em profundidade é uma técnica dinâmica e flexível, útil para apreensão de uma realidade tanto para tratar de questões relacionadas ao íntimo do entrevistado, como para descrição de processos complexos nos quais está ou esteve envolvido (DUARTE, 2013, p. 2). Para este estudo, a técnica foi realizada a partir de um roteiro-base, com questões abertas, que permitiu que a pesquisadora, ao receber uma resposta, não partisse diretamente para a próxima pergunta e, sim, aprofundasse o tema da pergunta anterior. Esse roteiro foi elaborado a partir de cinco questões principais: como está estruturada a assessoria de comunicação social do ministério?; quais são os principais produtos e serviços realizados dentro da estratégia de comunicação e como eles se integram?; quais são as principais atividades da rotina (dia a dia) do chefe da comunicação social?; qual é a visão da chefia da área sobre a gestão de comunicação? e quais as principais competências necessárias a um gestor de comunicação?.

Complementarmente, foi utilizado um questionário fechado, cujas respostas não foram aprofundadas, mas serviram como subsídio para a melhor compreensão do perfil básico dos entrevistados. As questões foram sobre idade, local de nascimento, sexo, titulação, data e forma de admissão no ministério, cargo ou emprego anterior, outras experiências nas iniciativas pública e privada e atuação em veículos de imprensa. A apresentação dos resultados das entrevistas, que se dá no item 3 , foi organizada por temas abordados e não por entrevistado ou órgão. Isso porque, como já foi dito, não é objetivo do estudo expor individualmente o perfil individual dos participantes.

\section{0 que dizem os autores e especialistas em gestão da comunicação}

Chaparro (2008, p. 39) considera razoável admitir que a atividade de assessoria de imprensa, tal como a entendemos hoje, tenha efetivamente surgido e se desenvolvido no contexto da crise de 1929, quando a informação passou a ser tratada mais fortemente como uma necessidade estratégica. "A crise de 1929 [...] representou [...] uma era de inovação, [...] porque a sociedade norte-americana [...] exigia ser informada, não apenas para saber, mas também para compreender o que estava acontecendo" (CHAPARRO, 2008, p. 39).

No contexto norte-americano, esse novo nicho no mercado da comunicação foi devidamente aproveitado pelos profissionais de relações públicas, que promoveram 
um crescimento físico, teórico e estratégico da atividade. Chaparro (2008, p. 39) conta que, em meados da década de 30, as Universidades de Yale, Harvard e Columbia criaram cadeiras da matéria e começaram a formar especialistas na carreira, que nas estruturas de ensino ficou vinculada ao campo da administração. Nos anos seguintes, esse modelo foi rapidamente exportado para o Canadá e países europeus.

Já no Brasil as relações públicas se desenvolveram principalmente a partir de 1964, no contexto da ditadura militar, e com forte estímulo do governo. Segundo Chaparro (2008, p. 44), não por acaso os jornalistas passaram a ser "generosamente" solicitados a ocupar o espaço crescente das assessorias de imprensa oficiais, sob tutela formal e/ou cultural de departamentos de relações públicas, para trabalhos que nem exigiam a presença física. "E sem precisar afastar-se das redações, para que viabilizasse o jogo duplo do duplo emprego".

Por outras motivações, mais mercadológicas, a iniciativa privada no Brasil também passou a reforçar os investimentos em comunicação por volta da década de 70 , especialmente as empresas do setor automotivo. Chaparro (2008, p. 45) destaca o caso dos jornalistas Reginaldo Finotti e Alaor José Gomes, que deixaram para trás veículos de comunicação como Folha de S. Paulo, Record e Última Hora para fundar a agência Unipress e montar o setor de imprensa da Volkswagen no Brasil. "A Unipress pode consolidar um modelo jornalístico de assessoria de imprensa, atuando, sobretudo, como alimentadora de pautas" (CHAPARRO, 2008, p. 45). Na sequência surgiram muitas outras empresas de assessoria de comunicação lideradas por jornalistas.

Essa trajetória da atividade no Brasil é descrita por Chaparro (2008, p. 47) como "uma experiência de assessoria de imprensa jornalística única no mundo". Segundo ele, a ocupação jornalística do segmento profissional da assessoria de imprensa se tornou um movimento irreversível, a ponto de, em 1995, um estudo feito pela subseção do Departamento Intersindical de Estatística e Estudos Socioeconômicos (Dieese) no Sindicato dos Jornalistas Profissionais do Estado de São Paulo ter revelado que cerca de um terço dos jornalistas com carteira assinada trabalhava fora das redações. "Ou seja, nas fontes”.

De acordo com Duarte (2008, p. 23), diversos cálculos de sindicatos e entidades indicam que, em 2008, pelo menos $50 \%$ dos jornalistas brasileiros já atuavam nas áreas relacionadas à comunicação organizacional. Hoje, esse número tende a ser ainda maior. Segundo reportagem de Kachani (2012), publicada pelo jornal Folha de S. Paulo, dados da Associação Brasileira das Agências de Comunicação (Abracom) indicam que mais da metade dos alunos graduados em jornalismo também acabam indo para essa área. "Mas a formação que recebem ainda é focada no trabalho em veículos de comunicação", disse ao repórter a presidente da Associação, Gisele Lorenzeti.

Duarte (2008, p. 236) explica que, na realidade atual, os objetivos das organizações deixaram de ser simples exposição na mídia para incorporar a noção de posicionamento estratégico junto aos públicos interno e externo. "As tarefas e os desafios ampliam-se, exigindo maior capacidade de criar e administrar diferentes instrumentos de comunicação", afirma.

Chegamos então ao conceito de comunicação integrada, um amplo conjunto de atividades - de jornalismo, publicidade, relações públicas, entre outras áreas da comunicação social - que regem, ou deveriam reger, a comunicação corporativa. "Já não há trabalho isolado, mas uma integração natural e que envolve visões institucionais e mercadológicas e que incorpora a exigência de uma comunicação interna eficiente", afirma Duarte (2008, p. 96). Ele reforça que, embora seja a parte mais visível da comunicação organizacional, a assessoria de imprensa não é a única e nem necessariamente a mais importante.

Kunsch (1986, p. 150) define comunicação integrada como uma filosofia que direciona a convergência das diversas áreas, permitindo uma atuação sinérgica e constituindo uma unidade harmoniosa, apesar das peculiaridades de cada área. "A convergência de todas as atividades, com base numa política global claramente definida e nos objetivos gerais da organização, possibilitará ações estratégicas e táticas de comunicação mais pensadas e trabalhadas com vistas na eficácia." (KUNSCH, 1986, p. 150).

Curvello (2008, p. 122) considera que o conceito de comunicação integrada sugere uma atuação conjunta e eficaz dos jornalistas, publicitários, propagandistas, relações públicas e profissionais do marketing, que ofereça às organizações instrumentos que realmente possam atender à demanda social por informação. Entretanto, na avaliação do autor, as relações entre essas especialidades da comunicação são complexas e a referida integração pouco se tem refletido na prática. "Muitas vezes, ela está presente como discurso e até orienta as estruturas formais, mas poucas vezes insere-se como política, como filosofia e como ação", assinala.

\footnotetext{
areas relacionadas à comunicação organizacional. Hoje,
} 
No artigo "A comunicação (des) integrada", Bueno (2013) concorda com Curvello. Ele destaca que a comunicação integrada significa não apenas que as atividades de comunicação estão articuladas, mas que elas se integram ao processo de gestão, de planejamento, de marketing e que obedecem a uma política e diretrizes comuns. "Quantas empresas (e quantas agências de comunicação) podem, efetivamente, dizer que isso ocorre?", questiona. Segundo ele, quase sempre, em boa parte das organizações, nem ao menos a comunicação interna e a externa estão articuladas.

Ainda assim a comunicação é cada vez mais considerada pilar estratégico das organizações atuais. Kotler (2000, p. 570) escreve que, graças ao desenvolvimento tecnológico, hoje as instituições podem se comunicar não apenas pela mídia tradicional (jornais, rádio, televisão), mas também por novos meios. "Ao diminuir os custos de comunicação, as novas tecnologias encorajaram muitas empresas a passar da comunicação de massa para uma comunicação e um diálogo pessoal mais direcionados”. $\mathrm{Na}$ reportagem escrita por Kachani (2012), publicada pelo jornal Folha de S. Paulo, o presidente da Associação Brasileira de Comunicação Empresarial (Aberje), Paulo Nassar, declarou: "Estamos passando por uma transformação radical. A comunicação se tornou peça fundamental para as corporações, com o papel de decifrar ameaças e oportunidades". Segundo a matéria, os investimentos em comunicação empresarial pularam de R $\$$,6 bilhões em 2001 para R\$ 8,2 bilhões em 2012.

De acordo com a reportagem (KACHANI, 2012), entre os serviços oferecidos por agências de comunicação no Brasil, os mais contratados por empresas são assessoria de imprensa (presente em 75\% dos contratos), eventos corporativos (em 70\% dos contratos) e comunicação interna (62\%). Com menor procura, também figuram na lista mensuração e avaliação (53\%), patrocínios (13\%), relações com investidores (10\%) e relações governamentais (9\%).

No texto "A Comunicação Empresarial como vantagem competitiva", Jorge (2013) ratifica que as corporações estão passando por fantásticas transformações nas últimas duas décadas, num processo que continuará nos próximos anos. Ele afirma que o impacto da Revolução da Informação já redesenha as empresas e o universo dos negócios e que a comunicação empresarial deve ter a real perspectiva dessas transformações. Ele entende que a comunicação contribui para a eficácia organizacional e cor- porativa quando ajuda a conciliar os objetivos da empresa com as expectativas de seus públicos estratégicos.

Jorge (2013) também defende que a área de comunicação das empresas esteja sempre ligada diretamente à presidência. "Subordinada a outros departamentos, fica praticamente impossível administrar a comunicação de forma estratégica”. Por outro lado, Curvello (2008, p. 132) chama atenção para o fato de que a simples localização no topo da pirâmide organizacional não garante que a área de comunicação assuma a tão propagada e desejada visão estratégica. Segundo ele, em muitos casos, os profissionais se refugiam nas "frondosas sombras" das tarefas diárias e abdicam das funções de prospectar cenários, montar diagnósticos, planejar, coordenar e avaliar.

Curvello (2008, p. 132) sugere que a maioria das assessorias de comunicação ainda é movida pela coletânea de notícias publicadas na imprensa, atendimento às demandas telefônicas, redação de releases e sugestões de pauta, entre outras atividades meramente operacionais. Ou seja, focam em atividades periféricas e não investem tempo e esforços nas atividades consideradas centrais para o sucesso da organização. E a solução não está necessariamente na estruturação da área, mas nos modelos mentais dos profissionais de comunicação, "hoje muito diferentes e afastados do negócio da organização" (CURVELLO, 2008, p. 133).

Nesse contexto, vale destacar também a importância da comunicação social nos órgãos públicos, tendo em vista que o governo foi um dos grandes catalisadores das relações públicas no Brasil. Garrido (2013) cita que, assim como a comunicação organizacional em geral, a comunicação pública deve ser tratada de maneira estratégica e planejada. O gestor de comunicação em órgãos públicos deve se atentar a todos os cuidados necessários também à comunicação corporativa, priorizando sempre a transparência e o melhor aproveitamento dos recursos do Estado, assim como qualquer outro gestor público. Porém, em sua reportagem publicada pelo jornal Folha de S. Paulo, Kachani (2012) aborda dificuldades técnicas de se construir imagem para instituições do governo, que mudam "a cada eleição ou mandato".

Em relação às competências necessárias nessa área, Duarte (2008, p. 24) menciona que não basta ter sido um ótimo jornalista em um importante jornal para se transformar em um bom assessor de comunicação. "É um trabalho de psicólogo, diplomata e bombeiro", definiu 
o presidente da agência CDN Comunicação Corporativa, João Rodarte, à reportagem escrita por Kachani (2012). Bueno (2008, p. 389) destaca a importância da capacidade de planejamento, avaliação e mensuração de resultados pelos assessores de comunicação. Ele lembra que apenas o clipping não é capaz de exprimir totalmente o trabalho do departamento. Diz que, antes mesmo de se chegar ao clipping, deve existir um planejamento calcado no conhecimento profundo da empresa ou entidade, do mercado e da imprensa. Segundo Bueno (2008, p. 400), depois do clipping deve existir, ainda, um mecanismo que conduza a uma verdadeira auditoria do trabalho.

Milhomem (2008, p. 314) lembra que boa parte do êxito profissional também depende da relação entre assessorado e assessor - o que implica habilidades para se relacionar e assessorar pessoas em cargos hierárquicos superiores. Bueno (2013) cita, no artigo "A comunicação (des) integrada”, o profissional de comunicação corporativa que nos encontros reservados se queixa da falta de autonomia, da mão pesada dos chefes e das pressões por resultados a qualquer custo. Pode-se dizer que faz parte das habilidades necessárias ao assessor de comunicação a capacidade de lidar e superar esses entraves.

Duarte (2008, p. 99) explica que, nesse mercado, há dois principais campos de atuação para o comunicador: o especialista, que realiza assessoramento de imprensa, produção de publicações, conteúdo na internet, entre outros; e o gestor da comunicação, que atua de forma mais política e estratégica, utilizando a comunicação como insumo na tomada de decisões, ajudando a organização ou o assessorado a definir rumo e ações.

Não há um critério fechado quanto à formação de origem dos gestores de comunicação social. Entre as competências básicas necessárias, Duarte (2008, p. 96) elenca a capacidade de gerenciamento e o aprimoramento de sistemas de comunicação e destaca que, para administrar a comunicação se deve ignorar a formação e habilidades específicas, pois a maior parte do arcabouço teórico que orienta essa função está espalhada pela literatura do jornalismo, de relações públicas, gestão do conhecimento, administração e nas variadas ramificações do marketing. "Não importa qual a origem do profissional, desde que tenha capacidade de administrar ampla diversidade de produtos e processos na busca por resultados específicos", diz Duarte (2008, p. 97).

O gerenciamento do processo global de comunicação não é atribuição pré-definida de nenhum dos subsistemas (jornalismo, relações públicas, publicidade e propaganda, entre outros) e, sim, do profissional melhor habilitado (PALMA, 1994 apud DUARTE, 2008, p. 97). Estrategista político, articulador, consultor, conselheiro, capacidade de relacionamento, administrador de conflitos, capacidade para ler e interpretar o meio ambiente, dominar os meios clássicos de comunicação e descentralizador de operações são algumas das habilidades do gestor de comunicação citadas por especialistas (PIVA, 1999 apud DUARTE, 2008, p. 97).

No Brasil, onde a maioria desses cargos é ocupada por jornalistas, há uma sensação de que o mercado ainda não "maturou" o profissional com formação (ou competências) adequada para a atividade. Para Duarte (2008, p. 97), muitas vezes falta aos gestores de comunicação brasileiros conhecimento, interesse e até a socialização com colegas mais experientes em comunicação organizacional. Muitos comunicadores têm responsabilidades estratégicas, mas preferem dedicar-se aos boletins informativos (CORRADO, 1994 apud DUARTE, 2008, p. 98). "Ainda não temos [...] profissionais [...] que entendam a comunicação organizacional no sentido sistêmico. Temos [...] profissionais de RP [relações públicas] com visão muito limitada, jornalistas bons de texto, mas com visão também limitada" (TORQUATO, 1995 apud DUARTE, 2008, p. 98).

Não há riscos em se buscar contribuições mais específicas do marketing como referências para essa reflexão. Kotler (2000, p. 27), por exemplo, afirma que gerentes de marketing precisam tomar inúmeras decisões, desde decisões fundamentais, como que características projetar em um novo produto, quantos profissionais de vendas contratar ou quanto gastar em propaganda, até decisões de menor importância, como o texto e a cor de uma nova embalagem. "Os executivos de marketing, cada vez mais, veem-se em primeiro lugar com gerentes, e depois como especialistas", diz (KOTLER, 2000, p. 116). O autor reforça, ainda, que o planejamento está se tornando um processo contínuo, para responder a condições de mercado que mudam a grande velocidade. "É por meio dele que se desenvolve e mantém uma adequação viável entre objetivos, habilidades e recursos da organização e suas oportunidades", (KOTLER, 2000, p. 116).

Mas segundo o Mapa da Comunicação Brasileira - Edição 2011, pesquisa publicada pela FSB Comunicações e coordenada por Caetano e Mello (2011, p. 9), no Brasil a comunicação corporativa é vítima da ausência de 
uma cultura de planejamento. De acordo com a pesquisa, nos órgãos públicos $33 \%$ dos gestores relatam cumprir nove ações básicas de planejamento; nas empresas de capital nacional essa porcentagem é de $58 \%$; e de $70 \%$ nas empresas de capital estrangeiro. "Quem planeja mede resultados. Os órgãos públicos são os que menos realizam monitoramento e avaliação" (CAETANO; MELLO, 2011, p. 9).

O estudo mostra que no setor público o cotidiano dos gestores da comunicação representa um grande desafio, pois a maioria desses profissionais começou a trabalhar antes de 1997, antes da popularização da internet, e agora precisa lidar com os desafios da interatividade (CAETANO; MELLO, 2011, p. 14). Para Barreiros (2011, p. 20), um gestor de comunicação e todos os profissionais da área devem ter uma visão ampla e sistêmica para fazer com que ações, mensagens e canais se voltem ao desafio de construção, consolidação e sustentação da marca e das causas a que está ligada. Nesse contexto, de acordo com ele, também são necessários coerência, clareza, congruência e compromisso.

Bueno (1995 apud DUARTE, 2008, p. 98) considera que a "cabeça do negócio da comunicação" estará, cada vez mais, no profissional de concilia competência técnica com uma visão gerencial moderna e que sabe vislumbrar, com lucidez, a íntima relação entre comunicação e negócios. "A esse profissional está reservado o comando. Pensando bem, ele merece o cargo", conclui o autor.

\section{Estudo qualitativo: o gestor de comunicação em dez ministérios brasileiros}

Como já foi detalhado, para o estudo qualitativo foram entrevistados dez gestores de comunicação que trabalham, ou trabalhavam na época (entre julho e setembro de 2012), em dez dos 15 maiores ministérios brasileiros. As entrevistas foram realizadas pessoalmente, a partir do método de entrevista individual em profundidade, com uma maioria de questões abertas e um pequeno questionário fechado. O grupo estudado tem, em média, 48 anos (entre os entrevistados, o mais velho tem 60 e o mais jovem 38). A maioria deles (50\%) vem da Região Sudeste, 30\% da Região Sul, 10\% do Centro-Oeste e $10 \%$ do Nordeste. Na amostra recortada, há equilíbrio de gêneros (cinco homens e cinco mulheres).

Indo ao encontro do que foi demonstrado anteriormente, a pesquisa confirma que $100 \%$ dos entrevis- tados são formados em jornalismo, sendo que dois deles possuem uma segunda graduação (um em publicidade e propaganda e o outro em física). Metade deles cursou pós-graduação: três são especialistas (lato sensu), em comunicação visual, comunicação integrada e em marketing e gestão de clientes; e três são mestres (stricto sensu), em jornalismo econômico, planejamento de comunicação institucional e em comunicação e cultura contemporânea. Um deles acumula os dois títulos. Nenhum fez doutorado.

A maioria absoluta dos entrevistados ocupa cargo comissionado, de direção e assessoramento superior (DAS) - apenas um é funcionário público de carreira (analista de comunicação), originário do Supremo Tribunal de Justiça e cedido para o ministério onde atua. $\mathrm{Na}$ ocasião das entrevistas, em média, eles ocupavam o cargo atual há menos de dois anos (um ano e dez meses). Cinco deles haviam assumido a função há um ano ou menos.

Metade dos gestores não tem experiência em comunicação corporativa em entidades privadas e a outra metade adquiriu tal experiência atuando em agências de comunicação com clientes na área privada. A maioria (80\%) trabalhou como repórter e/ou editor em veículos de imprensa. Apenas dois entrevistados declararam não ter atuado em empresas jornalísticas. Por sua vez, todos têm experiência anterior na comunicação pública.

Um dos pontos mais relevantes para a análise desse grupo é o fato de todos serem jornalistas. Esse resultado era esperado, ainda que os teóricos pesquisados garantam que a administração eficiente da área de comunicação não dependa de uma formação específica. Sabe-se que essa unanimidade se explica pelo histórico da profissão de assessor de comunicação no Brasil, mas vale lembrar que, mesmo assim, a reportagem de Kachani (2012) mostra que a formação em jornalismo oferecida pelas universidades ainda contempla timidamente a comunicação empresarial. Somando-se a isso, há o panorama trazido pelo Mapa da Comunicação no Brasil - Edição 2011, no qual $67 \%$ desses gestores começaram a trabalhar antes de 1997 e agora precisam lidar com os desafios da interatividade (CAETANO; MELLO, 2011, p. 14).

Se leva-se em consideração que metade dos gestores de comunicação entrevistados não cursou pós-graduação e que, dos que cursaram, três não se especializaram em temas ligados à comunicação corporativa, é possível pensar que a maioria dos chefes de comunicação estudados não é qualificada academicamente em sua fun- 
ção. E isso provavelmente explica porque o comportamento de jornalista muitas vezes sobressai ao de gestor.

A maioria dos entrevistados concordou com a afirmação de que sua forma de atuar como gestor é ancorada na experiência adquirida no mercado e não na academia. Muitos afirmaram que gostariam de cursar uma pós-graduação, mas que não o fazem devido à dificuldade de conciliar os estudos com a dedicação exigida pelo cargo de gestor.

Na prática, os desafios possíveis à função vão muito além do jornalismo. Passam por questões como gestão de recursos financeiros e de pessoal. O porte das equipes das assessorias de comunicação social dos ministérios visitados, por exemplo, é bastante variado. Há desde equipes com menos de 15 pessoas até times de mais de 50 . E as assimetrias não estão apenas no tamanho, mas também no formato, no orçamento, nas formas de contratação, nas atribuições, no protagonismo e, especialmente, na visão dos gestores.

Uma das diferenças estruturais que mais se destaca está na hierarquia das assessorias de comunicação dos ministérios visitados. Quem está realmente no comando é algo que varia entre as pastas. Isso porque, apesar de a maioria absoluta delas dispor do cargo formal de "chefe da assessoria de comunicação", não raro é dado um cargo de "assessor especial do ministro" para o profissional que comandará de fato o departamento, ficando no topo da hierarquia da área, inclusive acima do "chefe da assessoria de comunicação".

O fluxo de trabalho que se segue a partir dessa diferença é ainda mais variado: há casos em que a autoridade maior do setor (seja ele o assessor especial ou o chefe da assessoria de comunicação) deixa a gestão cotidiana da área para um "subchefe" e sai a campo para assessorar o ministro em tempo integral; e há casos em que a autoridade maior do setor é de fato o gestor da área, destacando um profissional da equipe para o acompanhamento permanente do ministro.

Dos dez ministérios visitados, oito possuem a figura do assessor especial do ministro como autoridade maior da comunicação. Em sete deles a autoridade maior (seja assessor especial ou chefe da assessoria de comunicação) acompanha o ministro em tempo integral.

Para essa pesquisa, a autora foi recebida por: sete profissionais que cumprem o papel de "subchefe" da área (seis deles no cargo de chefe da assessoria de comunicação e um no de chefe da assessoria de imprensa); e três que atuam como autoridade maior da área (um chefe da assessoria de comunicação e dois assessores especiais do ministro). A maioria lidera equipes de 25 a 35 pessoas, com funcionários comissionados, servidores públicos e/ ou prestadores de serviços (funcionários de agências de comunicação contratadas).

Em geral os gestores de comunicação estão insatisfeitos com o porte de seus times e atribuem alguns insucessos da área a esse gargalo. Entre as assessorias de comunicação mais enxutas - com até 15 pessoas e sem serviços de assessoria de comunicação contratados —, há uma reclamação recorrente não só quanto ao tamanho, mas também em relação à qualificação da equipe. Um entrevistado do Ministério dos Transportes relata não conseguir contratar jornalistas “mais qualificados", ofertando R\$ 2.500,00 ao mês. Queixa semelhante foi enfatizada no Ministério da Fazenda.

Enquanto nos times menores muitas vezes sequer há hierarquia abaixo do chefe da assessoria de comunicação, em geral as equipes maiores possuem, abaixo dessa chefia, coordenadores de subáreas (como jornalismo, mídias digitais, relações públicas e publicidade e propaganda). O desempenho dessa estrutura foi muito bem avaliado pela maioria absoluta dos entrevistados. Porém, é possível observar que nem sempre os cargos de coordenadores de subáreas existem formalmente no organograma da entidade.

A falta de institucionalidade das assessorias de comunicação em órgãos públicos foi destacada fortemente por um dos entrevistados. "Não tenho coordenadores das subáreas porque institucionalmente esses cargos não existem". Segundo ele, muitas vezes esse desenho é praticado informalmente, por meio da distribuição de DAS, cargo considerado "coringa" porque pode estar associado a diferentes atividades dentro do órgão. Eventualmente a área cresce ou diminui de acordo com a quantidade de DAS que é capaz de conquistar.

Não raro gestores entrevistados mencionaram a "perda” de DAS ao reclamarem da diminuição das equipes. Em muitos casos, foi possível associar a terceirização de mão-de-obra via licitação de agências de comunicação a esse cenário de vulnerabilidade, e essa solução costuma surgir em situações de crise ou de emergência. Isso explica, em parte, outra recorrente reclamação dos gestores: a baixa qualidade dos serviços licitados pelo órgão, resultante da baixa qualidade dos processos realizados às pressas. Um chefe de assessoria de comunicação en- 
trevistado contou já ter visto papelaria ganhar processo licitatório para ser "barriga de aluguel" para contratação de jornalistas.

A falta de institucionalidade traz dificuldades não apenas à estruturação das equipes, mas também à funcionalidade da gestão da área. Um dos entrevistados citou que os gestores e secretários de comunicação são como técnicos de futebol: "Vão e vêm, de acordo com o interesse e muitas vezes para promoção do assessorado". A rotatividade desses gestores é uma realidade visível e geralmente acompanha a troca de ministros - como já citado, os participantes deste estudo, por exemplo, estavam no cargo há menos de dois anos em média. Isso muitas vezes causa ausência de continuidade nas estratégias e na estruturação das assessorias de comunicação dos ministérios.

A ausência de institucionalidade e de continuidade no trabalho pode ser um dos principais obstáculos para o aprimoramento dos modelos de gestão da comunicação e, consequentemente, da superação das assimetrias e gargalos, mostrados pelos chefes da área e, ainda, para o sucesso em estratégias de comunicação integrada. $\mathrm{Na}$ prática, as atividades que recebem a maior parte dos esforços das equipes parecem se restringir a uma pequena gama de instrumentos de comunicação, especialmente os relacionados à rotina de assessoria de imprensa, tais como agendamento de entrevistas, produção de press releases e clipping.

Ao menos dois gestores declaram, por exemplo, não considerar essencial realizar publicidade e propaganda. "Não tratamos de assuntos ligados diretamente à sociedade e, portanto, não precisamos nos comunicar com o cidadão dessa forma", disse um entrevistado do Ministério de Minas e Energia. Outro refutou a possibilidade de trabalhar com esse instrumento. "Se me pedissem para, além do jornalismo, gerir publicidade, eu não toparia. Porque eu não sou publicitário".

"Aqui nós temos uma abrangência de pautas infernal. Isso faz com que a relação com a imprensa, que é permanente e diária, predomine sobre as demais áreas", explicou outro gestor. Para ele, o jornalismo é o pilar mais estratégico da comunicação hoje. "Há uma natural predominância, sim, da assessoria de imprensa. Comunicação pública é ser vitrine, e você não responde com campanha publicitária a escalada do Jornal Nacional. Até responde, mas a prazo", finalizou. Como esse, muitos gestores também declararam que, por ter uma rotina diária e impac- tante na imagem do órgão, é natural que a assessoria de imprensa receba maior atenção.

Foi possível observar ainda que a preferência pela assessoria de imprensa se deve não só ao perfil dos chefes (que são jornalistas) e ao imediatismo da ação, mas ao baixo custo de se trabalhar com mídia espontânea. Não raro, os entrevistados apontaram a falta de recursos financeiros como justificativa para não realizar comunicação integrada. Mas, apesar dos altos custos da publicidade (provavelmente a frente mais cara da comunicação social), é a área de relações públicas e eventos que parece ser a mais preterida nas estratégias de comunicação dos ministérios visitados. Em boa parte das pastas, esse ramo sequer está inserido no escopo da assessoria de comunicação. Um único caso, pareceu ir na contramão dessa realidade. No Ministério da Educação, a área de relações públicas e eventos é tratada como prioritária. "Essa ferramenta é fundamental para o desenvolvimento da política de comunicação social. Eu diria que ela é a ferramenta mais importante", afirmou o assessor especial responsável pela comunicação.

Apesar de ser a atividade mais comum nas áreas de comunicação, algumas vezes mesmo a assessoria de imprensa é realizada de forma desintegrada das demais atividades e até da missão institucional do órgão. Várias das assessorias de comunicação visitadas para esse estudo (geralmente as de menor porte) focam sua divulgação nos projetos, ações e políticas realizadas especificamente pelo ministro. "A estratégia de comunicação do nosso ministério é essencialmente para atendimento do ministro. Todos trabalhamos preferencialmente para atendê-lo", contou um entrevistado.

Essa priorização da divulgação das ações do ministro, em detrimento das demais atividades do órgão, está de certa forma refletida no contexto mencionado anteriormente, sobre os casos em que o chefe maior da assessoria de comunicação deixa a gestão cotidiana da área para um "subchefe" e sai a campo para assessorar o ministro em tempo integral. Isso ocorre em sete dos dez ministérios visitados.

A forma mais comum de integrar a comunicação apresentada pelos chefes entrevistados é a realização de reuniões periódicas (semanais, quinzenais ou mensais), nas quais os diferentes departamentos que integram a área se encontram e informam aos demais o que estão realizando. Todavia, isso não necessariamente se reflete na integração das ações, de seus objetivos e dos resultados. 
Aparentemente, a questão-chave dessa dificuldade é a ausência de planejamento estratégico na gestão, ainda que a capacidade de planejamento seja uma das competências mais importantes para um gestor de comunicação. Como mostra o Mapa da Comunicação Brasileira — Edição 2011 — , no Brasil a comunicação é vítima da ausência de uma cultura de planejamento e nos órgãos públicos apenas 33\% dos gestores relataram cumprir nove ações básicas de planejamento (CAETANO; MELLO, 2011, p. 9).

Dos gestores de comunicação entrevistados, uma minoria mencionou ações de planejamento espontaneamente. Na maioria dos casos, o tema só surgiu quando foram feitas perguntas específicas pela pesquisadora. Nesse momento, via de regra os entrevistados responderam que planejamento é, sim, fundamental, mas apenas três ou quatro conseguiram demonstrar como realizam a atividade realmente. Na prática, boa parte do grupo entrevistado pareceu conduzir as atividades da área dia após dia, especialmente a partir das rotinas da imprensa.

Alguns entrevistados declararam não ter condições adequadas para fazer planejamento. "O meu planejamento é no curto prazo, de uma semana. Eu tenho pouca gente, os produtos que já desenvolvemos absorvem 'pra caramba' e eu tenho cobertura jornalística diária e o acompanhamento das entrevistas todas", disse um deles. Entre os que demonstraram planejar, destacam-se o Ministério do Desenvolvimento Social e Combate à Fome, que mantém um profissional totalmente dedicado ao tema, o Ministério da Defesa, que está criando uma coordenação de planejamento dentro da assessoria de comunicação, e o Ministério da Educação, que realiza planejamentos de comunicação anuais.

Para o entrevistado do Ministério da Defesa, fazer apenas comunicação de improviso no dia a dia prejudica drasticamente os resultados perseguidos. "Você até consegue ter uma comunicação com a qual apague incêndios. Mas para ter uma comunicação estratégica, você precisa se planejar. [...] O esforço isolado das ações não vai levar a nada", declara. Ele considera estratégicas as ações que têm impacto direto e mensurável nos resultados da organização.

Porém, foi possível notar que, como reflexo da ausência de planejamento em comunicação, na maioria das gestões analisadas também é pouco frequente a realização de mensuração de resultados e produção de relatórios gerenciais. $\mathrm{O}$ instrumento de aferição de resultados mais apresentado pelos entrevistados é o clipping de notícias. Mas Bueno (2008, p. 389) lembra que apenas o clipping não é capaz de exprimir totalmente o trabalho do departamento. "Nós estamos fazendo um esforço enorme para andar na contramão da cultura de não aferição de resultados", comemorou o chefe da assessoria de comunicação do Ministério do Planejamento, um dos únicos a apresentar um método estruturado de mensuração de resultados durante as entrevistas.

Elencar as atribuições do gestor de comunicação foi, sem dúvida, o ponto mais sensível das entrevistas realizadas para o estudo. Nesse momento da abordagem, foi tomada como referência a descrição dada por Bueno (1995 apud DUARTE, 2008, p. 98), que considera que a "cabeça do negócio da comunicação" estará, cada vez mais, no profissional que concilia competência técnica com uma visão gerencial moderna.

Alguns entrevistados demonstraram dificuldades em dissociar o papel de jornalista assessor de imprensa que muitos ainda acumulam e desempenham - e o papel de gestor. Como citado anteriormente, a maioria deles acompanha diretamente o ministro em suas atividades diárias, atuando mais como assessor de imprensa do mesmo do que como gestor da assessoria de comunicação. E mesmo aqueles que não estão totalmente dedicados à assessoria direta do ministro, muitas vezes, demonstraram dar prioridade aos assuntos ligados à assessoria de imprensa, em detrimento das outras atividades de comunicação e de gestão. Boa parte se dedica muito mais ao monitoramento de mídia e ao atendimento de repórteres do que, por exemplo, a ações de publicidade, comunicação interna e eventos, tampouco de planejamento, de gerenciamento e de análise de desempenho da assessoria de comunicação.

Em geral, os poucos gestores que demonstraram conseguir equilibrar as atividades gerenciais e as de assessoria de imprensa reservam para si as demandas mais sensíveis ou de veículos de comunicação mais influentes, delegando ao restante da equipe os demais atendimentos de imprensa. "Se precisar, eu entro no circuito. Mas toda a nossa preocupação é ter uma atuação mais estratégica. Meu papel imediato é fazer a supervisão desse processo", reforçou um deles. "A assessoria de imprensa é hoje a parte mais visível e a mais sensível, então muitas vezes temos que canalizar os esforços para essa área porque é uma área de prevenção de crise", explicou outro entrevistado. “Tem que se organizar, se não a gente se perde. Eu separo 
horários para as atividades de assessoria de comunicação e para o administrativo", descreveu outro.

Atividades administrativas também são comumente delegadas pelos gestores. "Eu sou o gestor das verbas de publicidade e assessoria. Toda e qualquer contratação está sob minha responsabilidade. Mas minha assistente administrativa traz quase tudo pronto", falou um entrevistado. Outro gestor também contou que não realiza todas as atividades administrativas do cargo, delegando informalmente essas atividades a uma pessoa de perfil administrativo, na "base da confiança". "A gente não tem o know-how e nem a linguagem administrativa. E não vem ninguém te orientar ou explicar", reclamou.

"Quando eu vi que não daria conta, conversei com meu chefe e optamos por delegar a quem tem esse kno$w$-how, ainda que nós sejamos os responsáveis regimentalmente. Não dá para gerir tudo, senão eu vou enlouquecer." Essa mesma situação e a mesma opinião foram observadas em vários dos órgãos visitados para o estudo. Alguns entrevistados atribuíram essa realidade à falta de conhecimento técnico sobre as atividades administrativas e a maioria acusou falta de tempo para estar à frente dessa área, devido a sua grande dedicação à assessoria de imprensa.

Em um caso específico, o entrevistado destacou abertamente que não concorda que seja função do gestor de comunicação liderar a administração da área. "A pessoa, quando se torna gestor, cai na burocracia. E são coisas diferentes. $O$ gestor vai gerir contrato, não vai ficar ali na lida do jornalista." Ele foi além: "Ou bem você trata de uma coisa, ou bem você trata de outra. Eu não conheço ninguém, jornalista, que levou à frente essas duas coisas".

Diante desse cenário, pode-se concluir que o grupo de gestores estudado se dedica quase que exclusivamente às ações de comunicação, delegando a administração da área (como a gestão de contratos) a subordinados com perfil específico. Mais uma vez se observa que eles tanto os que saem a campo para acompanhar o ministro quanto os que permanecem na base - priorizam a rotina da assessoria de imprensa.

A cultura de comunicação dos órgãos - ou a ausência dela - também é, muitas vezes, determinante para o conjunto de desafios que o gestor da área enfrenta. No caso dos ministérios, é comum os gestores mencionarem, como dificuldades do dia a dia, a imaturidade da organização para assuntos de comunicação. Entre as justificativas mais apresentadas para essa imaturidade está a falta de continuidade entre uma gestão e outra. "É difícil dar continuidade ao trabalho do gestor anterior, que era totalmente diferente", disse um entrevistado. Outro destacou que todos os assessorados deveriam passar por media training e saber que a comunicação precisa ser informada de tudo. Contou que essa relação - de explicar para o assessorado o funcionamento e a importância da comunicação - às vezes é muito desgastante e prejudica os prazos do trabalho. "Me aborrece quando vou a uma reunião e alguém começa a criticar a estratégia de comunicação sem qualquer embasamento", contou um gestor. Para evitar isso, ele disse que nunca chega numa reunião com uma ideia e, sim, com um projeto, com metas, objetivos, cronograma, custos etc.

Essa noção sobre a importância de se transformar as ideias em projetos não é recorrente entre os chefes de comunicação entrevistados, o que pode explicar, em parte, suas dificuldades de implantar novos processos, produtos e serviços. A isso se soma à morosidade da burocracia, também destacada por eles como um grande desafio na implantação de processos, produtos e serviços que exigem licitações. Todo esse panorama pode refletir um ciclo perigoso, no qual a falta de conhecimento dos assessorados sobre a atividade de comunicação atrapalha a realização das ações da assessoria, que com suas ações prejudicadas entrega poucos resultados palpáveis, o que dificulta ainda mais a percepção do assessorado sobre a importância da área.

Todavia, como vimos anteriormente, a comunicação corporativa é, ao mesmo tempo, um pilar estratégico porém muito recente para as organizações de forma geral. Lidar com a falta de compreensão dos outros setores faz parte dos desafios dos gestores de comunicação e alguns dos entrevistados deste estudo estão conseguindo avançar na superação dos obstáculos, ainda que lentamente. De todo modo, as assessorias de comunicação visitadas parecem ainda ter um longo caminho nesse sentido.

Outro desafio recorrente no discurso dos entrevistados é a dificuldade de elaboração de estratégias eficientes dentro de um cenário no qual falta coordenação do governo federal. Foram citados vários casos de diferentes naturezas, mas resultantes desse mesmo problema. "As assessorias do governo precisam se relacionar muito mais. A Presidência da República precisa interagir mais", declarou outro gestor. Sobre essa questão, um entrevistado voltou a destacar a ausência de institucionalidade da área de comunicação dentro da estrutura do Ministério 
Brasileiro. "É preciso ter carreira de gestor de comunicação. Sem isso, não há como resolver o problema internamente".

Um dos gestores entrevistados também se dedicou a fazer uma intensa crítica à forma como o planejamento em comunicação pública ocorre dentro do governo federal. "Nós precisamos discutir mais comunicação pública, avaliar esses casos de maneira mais científica, mais segura. Transformar a experiência empírica numa coisa mais estrutural". O gestor reclamou que a Secretaria de Comunicação da Presidência da República só “olha” para o Palácio do Planalto. "Ela só olha para os ministérios quando o Palácio aponta. Eu temo que nós estejamos consolidando muito pouco da experiência que estamos vivendo, que é uma experiência interessante."

Ele se diz cansado de ouvir sugestões "extraordinárias" de gente que nunca gestou publicamente enquanto, não raro, experiências bem-sucedidas estão sendo descartadas sem sequer serem avaliadas - e isso num mesmo governo. "Isso é fruto, sobretudo, de uma pressão política”. Vale registrar o panorama descrito por esse gestor porque ele caracteriza fortemente o que foi observado durante as visitas realizadas para o estudo. Ainda que de forma menos consolidada, a maioria dos gestores mencionou, em algum momento, dificuldades oriundas de pressão política, do distanciamento da relação com o Palácio do Planalto e da ausência de um modelo de comunicação mais apropriado para os ministérios - que têm necessidades e desafios diferentes das instituições privadas, de onde é importada uma série de técnicas de gestão da comunicação.

E, ao se falar em técnicas de gestão da comunicação, questões-chave como "qual o perfil do bom gestor de comunicação?" e "que habilidades ele deve ter?" foram lançadas aos entrevistados. Quando questionados sobre a principal competência necessária para se exercer o papel de gestor, muitos responderam que é preciso saber "lidar com gente", referindo-se tanto à gestão de equipes, quanto ao atendimento de públicos externos e de assessorados. “O grande desafio é tratar com o ser humano e conseguir construir uma relação de confiança entre a comunicação e as outras áreas do ministério", completou outro gestor.

Além da habilidade de ter boas relações interpessoais, uma série de outras competências foi citada espontaneamente pelos gestores como sendo fundamentais para o exercício da função. São elas: ter experiência, capacidade de persuasão, de liderança, de negociação e de articulação, ser paciente, saber se impor, argumentar de forma não ingênua diante dos assessorados, apresentar ideias, vender os resultados, ser organizado, estabelecer prioridades, saber delegar, entre outras.

Quanto à formação em jornalismo, nem todos a consideram primordial. Entre os dois ou três que demonstraram isso, um citou: "Nenhuma função da comunicação social, isoladamente, dá conta da quantidade de tensões que são criadas nesse ambiente de interação com os seus públicos estratégicos”. Para ele, o gestor de comunicação social tem que ser, necessariamente, mais qualificado do quem um jornalista, um publicitário ou um relações públicas. "O gestor de comunicação tem que dominar os meios digitais, conhecer o funcionamento dos veículos de comunicação, as ferramentas da publicidade e saber do arsenal que ele tem nas relações públicas. Se falhar em uma dessas frentes, ele não gere”, mencionou outro.

Durante as entrevistas, a maioria dos entrevistados destacou muito mais a importância da experiência do que da formação acadêmica. "Num momento de crise, qual é o manual que se segue?", questionou um deles. "Segue-se a experiência e a confiança do assessorado", declarou. Quando perguntados sobre o papel do gestor da comunicação na organização, a maioria dos gestores não hesitou em afirmar que ele é estratégico e fundamental. Porém, ao mesmo tempo os entrevistados demonstraram certa dificuldade em explicar, na prática, sua real função como gestor.

Nesse contexto de aparente conflito entre discurso e prática, um dos entrevistados se destacou da maioria, ao assumir que considera muito difícil definir o papel do gestor de comunicação e, portanto, as habilidades que deve ter. Perguntado se ele se considerava um gestor de comunicação, revelou: "Eu não sei, porque eu não sei o que define isso. Eu só sei que sou muito precavido, responsável e vigoroso. E estou sempre alerta, sim, aos riscos que a gente corre. E não gosto de burocracia. Um jornalista gestor?", questionou. E logo respondeu: "Essa formação não tem que ser uma formação sine qua non. Um assessor de comunicação não tem que cuidar dessa coisa toda. Ele pode até cuidar, mas é uma tarefa hercúlea ter que assinar, que fazer despesa, que cuidar de contrato".

"Não dá para acompanhar isso no dia a dia e entrar na redação apenas para ver se aquele contrato está sendo cumprido. Se o cara for muito bom em gestão da comunicação ele não vai estar aqui. Vai estar na empresa 
dele ou teorizando", concluiu o gestor. E ele foi além: "Eu não vi nada que me convencesse de que é uma condição sine qua non o assessor de imprensa ter a formação universitária de gestor de comunicação. Pós-graduação em comunicação?", perguntou à pesquisadora. “Tem coisas muito mais importantes para cuidar. Vai fazer ciências políticas, para se estruturar. Economia, história, vai estudar! Assessoria de comunicação é saber o caminho, escrever bem, ter a cabeça organizada para cumprir aquilo. Só isso", respondeu ele.

Esse entrevistado afirmou ainda não ter visto o "desenho" do que seria um gestor de comunicação. "Eu acho isso uma balela! É coisa para não cumprir. É apenas mais um elemento, mais um penduricalho, para talvez justificar aí um salário, uma remuneração." Embora possa parecer destoante, a opinião desse gestor é bastante simbólica diante do que foi apresentado pelo grupo estudado. Apesar de haver uma grande diferença no discurso dos demais entrevistados em relação a esse, a não compreensão sobre o papel do gestor de comunicação, a ausência de qualificação específica nessa área e a maior dedicação a ações de jornalismo em detrimento de outras inerentes à função, evidenciadas na fala desse entrevistado, podem ser observadas, na prática, em várias pastas visitadas.

Todavia, para boa parte dos desafios apresentados pelos gestores de comunicação entrevistados parece haver soluções possíveis no curto, médio e longo prazos. Mas é preciso reconhecer a grande dificuldade de implementá-las no ambiente de burocracia morosa e de descontinuidade trazida pelas constantes mudanças de gestão, como destacaram os entrevistados.

$\mathrm{Na}$ maioria absoluta das assessorias de comunicação analisadas, observou-se um ponto muito positivo para implementar soluções: a proximidade com o mandatário, tendo em vista que são áreas ligadas ao gabinete do ministro e cujas chefias o assessoram diretamente na maioria das vezes. Em teoria, isso oportuniza o diálogo com a autoridade sobre os problemas e, portanto, facilita a conquista de ações estruturantes e transformadoras. Porém, vale lembrar que Curvello (2008, p. 132) chama atenção para o fato de que a simples localização no topo da pirâmide organizacional não garante que a área de comunicação assuma visão estratégica. Segundo ele, em muitos casos os profissionais se refugiam nas "frondosas sombras" das tarefas diárias e abdicam das funções de prospectar cenários, montar diagnósticos, planejar, coordenar e avaliar.
Curvello (2008, p. 133) acrescenta, ainda, que a solução não está necessariamente na estruturação da área, mas nos modelos mentais dos profissionais de comunicação, "hoje muito diferentes e afastados do negócio da organização". Esse panorama descrito por Curvello foi visível em vários dos ministérios visitados e parece refletir a simples continuação de culturas convencionais enraizadas nesses departamentos desde gestões anteriores.

$\mathrm{Na}$ avaliação da pesquisadora, os grandes desafios dos gestores entrevistados ainda são, provavelmente, buscar novos modelos de gestão da comunicação - que incluam planejamento e mensuração de resultados -, e alcançar um melhor aproveitamento do canal direto com o mandatário da organização para implementar esses novos modelos. E é possível dizer, grosso modo, que tais desafios configuram um processo de maior profissionalização da atividade, que uma minoria dos gestores já colocou em andamento.

\section{Conclusão}

Todos os anos centenas de profissionais ingressam na área de comunicação corporativa, cuja demanda é crescente. São geralmente jornalistas, muitos oriundos da imprensa, que, na maioria das vezes, executam estratégias de comunicação ancoradas mais na assessoria de imprensa do que às outras áreas da comunicação social. Dentro desse cenário, o presente estudo se propôs a contribuir para a reflexão sobre a gestão da comunicação nas organizações e sua relação tanto com conceitos estritamente de gestão como de comunicação integrada.

Foram observados os diferentes entendimentos de profissionais da área sobre o tema, elencadas atividades e desafios recorrentes no dia a dia dos gestores de comunicação, mapeados aspectos sobre competências e habilidades inerentes à função e apontadas convergências e divergências sobre o assunto encontradas durante a pesquisa. Tudo isso por meio de uma importante revisão bibliográfica, além do desenvolvimento de um estudo qualitativo a partir de entrevistas com os chefes das áreas de comunicação social de dez dos 15 maiores ministérios brasileiros, segundo a Lei Orçamentária Anual de 2012.

Uma das principais conclusões possíveis do estudo é a existência de grandes assimetrias nas assessorias de comunicação social dos ministérios visitados, tanto no porte das equipes quanto no rol de atividades de comunicação realizadas e na capacidade orçamentária, o que 
gera uma ampla gama de desafios de comunicação a serem superados pelas chefias dessas áreas. Por outro lado, observa-se uma tendência padrão de não planejamento, não mensuração de resultados, não priorização da comunicação institucional e não qualificação e profissionalização da função de gestor de comunicação.

Em resumo, na percepção da pesquisadora, o estudo mostra que o perfil básico do grupo estudado tem cerca de 50 anos, vem da Região Sudeste, é jornalista, ocupa um cargo comissionado, está na função há menos de dois anos, já trabalhou na imprensa e tem experiência anterior em comunicação pública. A atuação desse gestor-médio está calcada mais nas atividades de comunicação do que de gestão, principalmente na assessoria de imprensa e, ainda, dentro desse recorte, na assessoria de imprensa do ministro. Esse gestor assessora mais do que consegue planejar e atribui isso à falta de condições para planejamento - tempo, institucionalidade, continuidade do trabalho e coordenação do governo. Nesse contexto, enfrenta considerável dificuldade para promover comunicação integrada e realizar mensuração de resultados.

Além disso, esse gestor-médio pouco realiza atividades administrativas, porque não se considera apto e nem prioriza esse campo. Reconhece como habilidades fundamentais para seu cargo, além daquelas relacionadas à assessoria de imprensa, as competências ligadas a relações interpessoais. Ele não tem qualificação acadêmica na função que realiza e considera mais importante ter experiência, uma formação conquistada ao longo da carreira, no mercado. Eventualmente, ele até questiona a necessidade de aprimorar competências de gestão e administrativas.

Vale destacar, como sabiamente disse Triviños (1987, p. 17), que "os fenômenos e objetos do mundo não constituem um amontoado de coisas acabadas, mas em constante transformação". Como dito no início desse trabalho, a presente pesquisa não foi desenvolvida com a intenção de tratar a temática como uma verdade definitiva ou absoluta. Na avaliação da autora, é possível encontrar no Ministério Brasileiro boas práticas de gestão da comunicação integrada. E, apesar de essas boas práticas ainda não serem predominantes, podem se tornar uma nova tendência se houver uma ação mais coordenada do governo federal para integração e apoio aos seus gestores de comunicação. Segundo a autora, é essencial também o constante exercício da autoavaliação, reflexão e busca por novos conhecimentos por parte desses profissionais, cujo trabalho é essencial para a transparência da gestão pública e, de forma geral, para a democracia.

\section{Referências}

BARREIROS, Carlos Alberto. A comunicação e sua relação com o r n ing. In: CAETANO, Rodrigo; MELLO, Rachel. Mapa da comunicação brasileira: edição 2011. Brasília: FSB Comunicações, 2011. p. 20-21.

BUENO, Wilson da Costa. A comunicação (des)integrada. Disponível em: <http://www.comunicacaoempresarial. com.br/comunicacaoempresarial/artigos/comunicacao_ corporativa/artigo2.php>. Acesso em: 27 mar. 2013.

BUENO, Wilson da Costa. Medindo o retorno do trabalho de assessoria de imprensa. In: DUARTE, Jorge (Org.). Assessoria de imprensa e relacionamento com a mídia: teoria e crítica. São Paulo: Atlas, 2008. p. 389-400.

CHAPARRO, Manuel Carlos. Cem anos de assessoria de imprensa. In: DUARTE, Jorge (Org.). Assessoria de imprensa e relacionamento com a mídia: teoria e crítica. São Paulo: Atlas, 2008. p. 33-51.

CURVELLO, João José Azevedo. Legitimação das assessorias de comunicação nas organizações. In: DUARTE, Jorge (Org.). Assessoria de imprensa e relacionamento com a mídia: teoria e crítica. São Paulo: Atlas, 2008. p. 121-137.

DUARTE, Jorge. Apresentação. In: DUARTE, Jorge (Org.). Assessoria de imprensa e relacionamento com a mídia: teoria e crítica. São Paulo: Atlas, 2008. p. 23-26.

DUARTE, Jorge. Assessoria de imprensa no Brasil. In: DUARTE, Jorge (Org.). Assessoria de imprensa e relacionamento com a mídia: teoria e crítica. São Paulo: Atlas, 2008. p. 81-99.

DUARTE, Jorge. Assessoria de imprensa: o caso brasileiro. Disponível em: <http://www.comunicacaoempresarial. com.br/comunicacaoempresarial/artigos/assessoria_imprensa/artigo3.php>. Acesso em: 27 mar. 2013.

DUARTE, Jorge. Entrevista em profundidade. Disponível em: <http://www.google.com.br/url?sa=t\&rc$\mathrm{t}=\mathrm{j} \& \mathrm{q}=\& \mathrm{esrc}=\mathrm{s} \&$ source $=$ web $\& \mathrm{~cd}=1 \& \mathrm{cad}=\mathrm{rja} \& \mathrm{ve}-$ $\mathrm{d}=0 \mathrm{CDEQFjAA} \& \mathrm{url}=\mathrm{http} \% 3 \mathrm{~A} \% 2 \mathrm{~F} \% 2 \mathrm{Fxa} . \mathrm{yimg}$. com\%2Fkq\%2Fgroups\%2F21729374\%2F795258217\%2 Fname $\% 2$ FEntrevista $\% 2$ Bem $\% 2$ Bprofundidade. doc\&ei=VSJTUei7JM670AGh6oGwAQ\&usg=AFQjCNG1oY7TDYBSRfQmbuWdj0drqRpD3A\&sig2=w6zTXHPq4khHXVqahXCR5A\&bvm=bv.44342787,d. dmQ>. Acesso em: 27 mar. 2013. 
DUARTE, Jorge. Produtos e serviços de uma assessoria de imprensa. In: DUARTE, Jorge (Org.). Assessoria de imprensa e relacionamento com a mídia: teoria e crítica. São Paulo: Atlas, 2008. p. 236-255.

GARRIDO, Bruno Sampaio. Comunicação entre órgãos públicos: limites entre a intenção e a realização. Disponível em: <http://www.bocc.ubi.pt/pag/garrido-comunicacao-bocc-05-09.pdf>. Acesso em: 27 mar. 2013.

JORGE, Miguel. A comunicação empresarial como vantagem competitiva. Disponível em: <http://www.comunicacaoempresarial.com.br/comunicacaoempresarial/ artigos/comunicacao_corporativa/artigo5.php $>$. Acesso em: 27 mar. 2013.

KACHANI, Morris. Área de comunicação corporativa aumenta $300 \%$ em dez anos. Folha de S. Paulo, São Paulo, Caderno Mercado, p. B10, 29 set. 2012.

KOTLER, Philip. Administração de marketing: a edição do novo milênio. São Paulo: Prentice Hall, 2000.
KUNSCH, Margarida. Planejamento de relaçőes públicas na comunicação integrada. 1986. Disponível em: $<$ http://books.google.com.br/books?id=Q1ZFmcZ-

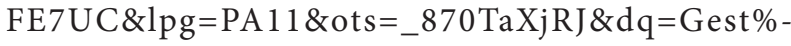
C3\%A3o\%20integrada\%20da\%20comunica\%C3\%A7\%C3\%A3o\%20organizacional\%20e\%20os\%20desafios\%20 da\%20sociedade\%20contempor\%C3\%A2nea\&lr\&hl=p$\mathrm{t}-\mathrm{BR} \& \mathrm{pg}=\mathrm{PA} 11 \mathrm{H}=$ onepage\&q\&f=false $>$. Acesso em: 27 mar. 2013.

MILHOMEM, Luciano. Relacionamento assessor/assessorado: entre tapas e beijos. In: DUARTE, Jorge (Org.). Assessoria de imprensa e relacionamento com a mídia: teoria e crítica. São Paulo: Atlas, 2008. p. 314-324.

TRIVIÑOS, Augusto Nibaldo Silva. Introdução à pesquisa em ciências sociais: a pesquisa qualitativa em educação. São Paulo: Atlas, 1987.

\section{Agradecimentos}

Agradeço aos meus entrevistados pela colaboração, ao professor orientador do trabalho pela confiança e inspiração profissional, aos demais professores pelos ensinamentos, aos colegas de trabalho pelo apoio fundamental na operacionalização do estudo aqui relatado e à minha família pelo incentivo de sempre. 